\title{
Kroničari i povjesničari o prvom po imenu poznatom trebinjskom biskupu Ivanu
}

\section{Uz 200-godišnjicu smrti posljednjega trebinjsko- (mrkansko)ga biskupa Nikole Ferića}

IVICA PULJIĆ

Neum

E-pošta: don.ivica.puljic@tel.net.ba

\author{
UDK: 262.3(497.6 Trebinje) \\ 929 Ferić N \\ Pregledni rad \\ Primljeno: 20. svibnja 2019. \\ Prihvaćeno: 19. lipnja 2019.
}

Sažetak

Sa sigurnošću je utvrđeno da je Trebinjska biskupija uspostavljena u drugoj polovici X. stoljeća i nije čudo što nam nisu očuvani ni dokumenti njezine uspostave ni imena njezinih prvih biskupa, jer su nam čak i imena vladara iz toga stoljeća slabo poznata. Kako se ove, 2019., godine navršava 200 godina od smrti posljednjega trebinjsko-mrkanskoga biskupa Nikole Ferića (1792. - 1819.), prigoda je da iznesemo što je legenda a što povijesna istina $\mathrm{u}$ raznim popisima o prvom njezinu po imenu navedenu biskupu Ivanu. U ovom prikazu iznosi se ono malo napisanoga o spomenutom prvom trebinjskom biskupu Ivanu o kome nalazimo vijesti u starim kronikama te ga se pokušava, s manjom ili većom vjerojatnošću, smjestiti u vrijeme njegova djelovanja.

Ključne riječi: Trebinjska biskupija; trebinjski biskup Ivan; Trebinje; Tribunija-Trebinje; Diokleja; Epidaurum; Dubrovnik; Bar. 
U višestoljetnoj grčevitoj borbi između Dubrovnika i Bara za metropolitansko pravo nad biskupijama Gornje Dalmacije nastale su mnoge tradicije, brojni zapisi kroničara i nešto malo sigurno autentičnih izvora na čemu se temelje teorije brojnih starijih i novijih autora o ovome problemu. ${ }^{1}$

I tekstovi dubrovačkih kroničara i pisaca, koji donose ime prvoga imenom navedena trebinjskoga biskupa Ivana, oslanjaju se na tekst Dukljaninova ljetopisa kome onda dodaju i u njegovo pisanje ugrađuju svoje spoznaje i nastavljaju dalje pisati povijest tamo gdje je Dukljanin stao. Spomenuti Dukljaninov spis znatno je stariji od njihova vremena, čak nekoliko stoljeća. Nastanak mu istraživači stavljaju u drugu polovicu XII. stoljeća, kada ga je na latinski preveo neki barski prelat, u novije se vrijeme misli da je to bio upravo barski nadbiskup Grgur Barski (1172. - 1194./1196.), ${ }^{2}$ i nadopunio drugim kronikama $^{3}$ te vlastitim dodatcima, uglavnom onim s prozirnim ciljem da se utvrdi pravo Bara na nadbiskupsko metropolitansko sjedište. To što se kroničari često međusobno ne slažu, svjedoči da im djela nisu jednostavni prijepisi nego da su prilično neovisni u pisanju, a možda čak pišu i na temelju različitih predložaka pa i izvora, na osnovi kojih donose vlastite zaključke. Uglavnom im je svima polazište Dukljaninov ljetopis pa je nužno pomno proučiti tekstove njegova ljetopisa da bi se moglo shvatiti ono što kroničari u njega umeću ili dodaju u određeno njegovo pripovijedanje. I tekstovi koji navode ime

1 O uspostavi i početcima Dubrovačke i Barske metropolije pišu odreda svi kroničari počevši od Dukljanina pa do kasnijih dubrovačkih pisaca. Ovdje od znanstvenih studija navodimo samo neke: MiHo BARADA, "Dalmatia Superior", u: Rad JAZU, 270, Zagreb, 1949., str. 93-113; Dominik MANDić, "Osnutak dubrovačke metropolije", u: Rasprave i prilozi iz stare hrvatske povijesti, Rim, 1963., str. 266-283; StJePAn Krasić - Serafino RazzI, Povijest dubrovačke metropolije i dubrovačkih nadbiskupa, Dubrovnik, 1999.; IvICA PuljIĆ, "Uspostava dubrovačke metropolije", u: Nediljko A. Ančić (prir.), Tisuću godina uspostave dubrovačke nadbiskupije, Dubrovnik, 2001., str. 15-56; IVAN MARKOvić, Dukljansko-barska metropolija, Zagreb, 1902.; IVAN Jovović, Iz prošlosti dukljansko barske nadbiskupije, Bar, 2004.

2 EdUARD PERIČIć, Sclavorum regnum Grgura Barskog, ljetopis popa Dukljanina, Zagreb, 1991., osobito str. 198-214; I. Jovović, nav. dj., str. 63-66, 221.

3 Ljetopis se u velikom dijelu slaže s tzv. Hrvatskom kronikom (koju V. Mošin donosi ispod teksta paralelno s Dukljaninovim tekstom i prijevodom na hrvatski). U samom djelu jasno se nazire i neka izgubljena trebinjska kronika (rodoslov) kao i životopis dukljanskoga vladara Ivana Vladimira. V. Mošın, nav. dj., str. 33-34; I. Jovović, nav. dj., str. 35-40. 
trebinjskoga biskupa zapravo su umetak u kraći Dukljaninov tekst u poglavljima XXVI. i XXVII., čije dijelove zato opširnije citiramo i to, olakšano razumljivije, na hrvatskom jeziku kako ih donosi izdanje Vladimira Mošina. ${ }^{4}$

Dukljanin u navedenim poglavljima opisuje kako je, nakon pogibije Časlava i raspada jake Raške države, došao iz progonstva iz Rima na prijestolje svojih otaca sin vladara Petrislava, unuk kralja Radoslava, imenom Pavlimir. Njega su, zbog izrazitih ratnih sposobnosti i uspjeha prozvali jednostavno Bello (ratnik). Obično se upravo spomenuti nadimak ovoga vladara poistovjećuje s navodom cara Konstantina Porfirogeneta kada piše o trebinjskom županu Krajini da je sin "trebinjskoga župana Belaja". ${ }^{5}$ Dukljanin za Belu Pavlimira piše da se razvio u "vrlo jaka i hrabra junaka, tako da mu u gradu Rimu nije bilo ravna" pa mu rodbina i drugi Rimljani promijeniše ime u Bello - Belimir jer je veoma volio ratovati. ${ }^{6}$ Zbog novonastalih neprilika $\mathrm{u}$ Rimu on se sa svojom rimskom rodbinom i pratnjom uputio preko Apulije u Dalmaciju i stigao u luku "koja se zove Gruž i Umbla". Dukljanin dalje doslovce kaže: "Kad su čuli banovi i župani u zemlji, da je došao Bello, unuk kralja Radoslava, obraduju se, a najviše narod slavenske zemlje; počeše priticati $\mathrm{k}$ njemu sa svih strana, naročito stanovnici tribunjskog okružja, koji dođu is velikom počašću odvedu ga u Tribunju. Zatim dođu u Tribunju banovi, koji ga sa županima i satnicima primiše s poštovanjem i na dan Uzašašća Gospodnjeg postave ga za kralja."7 Nakon pobjede protiv Raške i drugih neprijatelja, došao je u jedan grad Tribunie te u njemu umro naprasnom smrću i sahranjen "s velikom počašću u crkvi sv. Mihaela u istom gradu". ${ }^{8}$ Kako je biskupija sve do danas pod zaštitom sv. Mihaela, to bi bio prvi spomen trebinjske katedrale. Dukljanin ne navodi tko je Belu Pavlimira ustoličio, a kako se obično krunjenje i ustoličenje vladara odvijalo i u crkvenom obredu, pretpostaviti je da je to učinio i u ovom slučaju neki trebinjski biskup jer je, prema samom Dukljaninu, Trebinjska biskupija već postojala (naveo ju je mnogo prije, u IX.

4 V. Mošın, nav. dj., str. 69-72. Tekstove su s latinskoga preveli Stjepan Mencinger i Vjekoslav Štefanić.

5 Usp. izdanje: Konstantin Porfirogenet, O upravljanju carstvom, Dom i svijet, Zagreb, 2003., poglavlje XXXIV., str. 89, 280.

6 V. Mošin, nav. dj., str. 69.

7 Isto, str. 71.

8 Isto, str. 72 . 
poglavlju, gdje govori o saboru "in planitie Dalmae" u vrijeme kralja Svetopeleka koga je obratio "muž Božji Konstantin, a kome je poslije papa Stjepan, kad ga je zamonašio, nadjenuo ime Kiril",9 (sv. Ćiril je živio 826./827. - 869.). Navođenje Trebinjske i drugih biskupija u Dukljanskoj metropoliji, ${ }^{10} \mathrm{~s}$ pravom se pripisuje sastavljaču Dukljaninova ljetopisa da time utvrdi metropolitansko pravo nadbiskupa Bara, nasljednika tobožnje Dukljanske metropolije.

Spomenuti Dukljaninov tekst, kako je već rečeno, glavni je izvor dubrovačkim kroničarima u koga uklapaju i druge tradicije koje su im bile dostupne, a možda i neke autentične izvore, na kojima donose svoje zaključke ili domišljanja. Njihov tekst, u kome navode ime biskupa Ivana, koji je dočekao vladara Belu Pavlimira u Gružu i kasnije ga ustoličio na Uzašašće u Trebinju, navodimo po vremenskom slijedu njihova života, jer za neke ne znamo godinu kada su dovršili svoje djelo.

1. Prvi spomen trebinjskoga biskupa Ivana nalazimo u dubrovačkoga pisca Ludovika Tuberona (Aloysius de Crieva, Cerva, Cervinus, Cervarius Tubero, 1458. - 1527.). Pišući o "Polimiru nadimkom Belo" koji se iskrcao u Gružu, kaže da je na tom mjestu radosno dočekan "a Joanne Tribuliensium Pontifice" i prvakâ kraljevstva te svečano odveden u grad Trebinje koji "eo tempestate pro captu Illyrico erat opulentum". ${ }^{11}$ Iz ovoga dodatka Dukljaninovu tekstu koji je iz neke poznate dubrovačke tradicije ili izvora, Tuberon, osim imena trebinjskoga biskupa Ivana, donosi i važnu tvrdnju da je u to doba trebinjska oblast (Tribunija - Trebinje) bila glava Ilirika, tj. širega okružja.

9 V. Mošin, nav. dj., str. 48-49. Hrvatska kronika, koja po svemu sudeći ima isti predložak s koga je Dukljanin prevodio na latinski svoje Kraljevstvo Slavena, zove to kraljevstvo kraljevstvom "Svetoga-puka", mudrog i dobrog Budimira. Nav. dj., str. 49. Događaji se datiraju u oba djela vremenom sv. KonstantinaKonstanca (Ćirila) i pape "Stipana", što se teško može posve uskladiti.

10 V. Mošın, nav. dj., str. 54.

11 "...Polimirus posteaquam in Dalmatiam navibus appulit, in portu qui, XIII. circiter ab urbe Rhacusa abest... se suosque exponit... una cum liberis, ac conjugibus in Illyricum proficiscentem sunt secuti. Eo loci a Joanne Tribuliensium Pontifice, Regnique Principibus, qui officii gratia obviam novo Regi frequentes progressi erant, laetis animis, summoque honore est exceptus, atque in Oppidum Tribulium, quod sane ea tempestate pro captu Illyrico erat opulentum, deductus, quo sibi cum insignibus Imperii de more acceptis Regnum iniret." Ludovik Tuberon, Ludovici Cervarii Tuberonis comentaria suorum temporum, Tipografija Caroli Antonii Occhi, Ragusii, 1834., knjiga I., str. 190-191. 
2. Slično kao Tuberon piše i kroničar Nikša Ranjina (Nicolaus de Ragnina, 1494. - 1577. ili 1582.), također s nekim vlastitim zanimljivim opaskama, vjerojatno iz neke druge tradicije. Ranjina piše kako je spomenuti kralj posvećen na Uzašašće u Trebinju, a učinio je to epidaurski nadbiskup Ivan $s$ trebinjskim biskupom, ${ }^{12}$ kojemu on ne spominje ime. I on polazi od Dukljanina, ali se s njime ne slaže u pojedinostima: on kralja zove "...Radoslavo, ovvero Paulimiro cognominato" kome su Rimljani dali ime Bello, a bio je sin Stjepana sina kralja Radoslava koji je, prema Dukljaninu, zapravo Pavlimirov otac! Ne slaže se u tome ni s Tuberonom i to ne samo u imenu, nego i u ustoličitelju kralja: on naime piše da je kralja u Trebinju okrunio epidaurski nadbiskup Ivan s trebinjskim biskupom čije ime ne spominje. Kako u Epidaurumu nikada nije bilo nadbiskupa, a ni u Dubrovniku do kraja X. st. i pape Grgura V. (996. - 999.) kako slijedi iz bule pape Benedikta VIII. (1022. - 1024.) iz 1022., godine, ${ }^{13}$ može se zaključiti da je i u Ranjine trebalo biti riječi o trebinjskom

12 "...et in quel tempo essendo Raoslavo huomo valente et degno, lo fecero capitano dell'exercito loro. Dopo, constretto dalle preghiere delli suoi baroni, si maritò in una donna Romana di nobil prosapia, con la qual hebbe tre figliuoli, de quali ne moritero due di peste, et lo terzo restò nominato Stefano, et cognominato Petrislavo. Et re Radoslavo visse in gran vecchiezza, poi (ha) lassato l'anima a Dio, e $(f u)$ sepellito honorevolmente alla chiesa di s. Giovanni Laterano. Poi la morte del quale pigliò el governo della militia suo fiolo Stefano, in loco paterno; quale poi, pigliato la moglie, hebbe uno fiolo, allo qual pose il nome Radoslavo, ovvero Paulimiro cognominato. Qual, poi la morte, governò la militia in loco paterno; e perchè grandemente si dilettava in guerra, per tal causa li Romani li imposero nome Bello, e per altro nome non lo volevano chiamar. Ciaslavo, Berislavo cognominato, maledetto dal suo padre re Radoslavo, cominciò regnare quest' anno in Bosna, et visse in gran vecchiezza. ..."

O ustoličenju Ragnina piše: "Radoslavo re, havendo costruito la città, o vero el castello, con tutti li baroni et signori si partì de lì; et pervenuti in Tribunia, ivi honorificamente fu ricevuto, in ella festa della Ascensione, in re di Bosna da tutti. Fu consacrato, presente ivi lo arcivescovo Joanne Epidaurino collo vescovo di Tribunia, con tutti li bani, giupani, signori et altri principi di regno." Ragnina navodi i citat iz stihova kako su stanovnici Epidaura preselili i Ivana, koji je već bio nadbiskup prije rečenoga grada, u "urbs Ragusina". SpERATus (Natko) Nodilo, Annales Ragusini Annonymi item Nicolari de Ragnina, u: Monummenta spectantia Slavorum Meridionalium, vol. XIV., Zagrabiae, 1883., str. 170, 174-175.

13 Državni arhiv u Dubrovniku (odsad: DADU), bečka skupina. Jakov STIPIŠIĆ - Miljen ŠAmŠAlović (sakupili i obradili), MARKo KostrenčIć (uredio), Codex diplomaticus - Diplomatički zbornik, I., (dalje: CD, I.) Zagreb, 1967., str. 61-62. 
biskupu Ivanu. Zanimljivo je ovdje primijetiti kako ime Ivan upravo u ključnih prelata u ovim i drugim tradicijama na ovim širim prostorima izrazito dominira, $i$ to do te mjere da se čini kako je riječ o istoj osobi! Posebno je to upadljivo u djelu, o kome će domalo biti riječ, talijanskoga dominikanca Serafina Razzia s naslovom Narazioni o vero storia degli arcivecovi della Raugia koji u samo nekoliko rečenica opisuje čak pet nadbiskupskih sjedišta ${ }^{14}$ i u svakome je od njih prvi nadbiskup Ivan! U početku piše kako je epidaurski nadbiskup Ivan izbjegao u Trebinje i tamo prenio ne samo sjedište nego i titulu nadbiskupije te u Trebinju boravio kao nadbiskup "godine mnoge". Tako bi Trebinje "kroz godine mnoge" bilo nadbiskupsko sjedište epidaurskoga nadbiskupa Ivana. Spomenuta nadbiskupska stolica u Trebinju zatim je jedno vrijeme bila upražnjena. Dalje piše kako je bugarski car poslije svoga pokrštenja, uz dopuštenje pape Nikole I. (858. - 867.), prenio spomenutu nadbiskupiju iz Trebinja u grad Diokliju. ${ }^{15} \mathrm{U}$ popisima se tako redovito navodi i kao prvi dukljanski nadbiskup Ivan. ${ }^{16}$ Razzi dalje piše kako su Bugari i Grci u borbama razorili Diokliju pa se nadbiskup nastanio na školju Mrkan odakle je, zbog trajnih napada Saracena, dopuštenjem pape Benedikta V. (964.) prenio "dostojanstvo i naslov nadbiskupije" u Dubrovnik. ${ }^{17}$ Tako se

14 S. Krasić - S. Razzi, nav. dj., osobito str. 95-112.

15 Isto, str. 110-111. "Quando, circa gli anni di Nostro Signore CCCCXL Raugia Vechia, o vero Epidauro, città nobilissima, fu rovinata dai Goti, Giovanni epidaurino, che in quella resideva Arcivescovo, se ne fuggì in Tribunia, città così detta, in quella transferendo il titolo della sua chiesa, e l'Arcivescovado; e qui per molti anni dimorò. Essendo dopo istata dibellata e vinta la Rascia e la Bossina, con tutto l'aderente paese, della tiranida degli infedeli e scismatici, restò detta Chiesa certo tempo senza Pastore alcuno". "Lanno dopo 863 al tempo di Papa Niccola primo, essendosi convertito alla fede cattolica lo Imperatore di Bulgaria, con assenso di detto Papa fu transferito l'Arcivescovado di Tribunia alla città di Dioclia." S. Krasić - S. RAZZI, nav. dj., osobito str. 111.

16 Daniele Farlati - Jaсовo Colleti, Illyrici sacri, VII., Venetiis, 1817., str. 6; Krunoslav Draganović, Opći šematizam Katoličke Crkve u Jugoslaviji - Cerkev v Jugoslaviji 1974., Zagreb, 1975., str. 645; I. MARкоvić, nav. dj., str. 187; I. Jovović, nav. dj., str. 221.

17 "...e finalmente intormo all'anno 980, per la rovina eziandio di Dioclia, fatta da i Bulgari e da i Greci, l'Arcivescovo, che era in quel tempo, mutando la stanza sua, se ne venne prima alla picciola isola ò vero scoglio di Mercana, luogo vicino ad Epidauro, sedia antica. Ma conoscendo poscia che quivi non istava sicuro, per le rovine, e danni, i quali continovamente facevano i Saracini, scorrendo con i loro legni per tutto l'Adriatico mare, lasciato lo scoglio predetto de Mercana, venne ad habitare in Raugia nova, città fortificata e si- 
i prvi dubrovački nadbiskup zove opet Ivan! Doista u popisu epidaurskih prelata navodi se kao posljednji nadbiskup Ivan, a u popisu dubrovačkih opet je prvi nadbiskup Ivan! ${ }^{18}$

3. Treći spomen trebinjskoga biskupa, također na temelju Dukljanina te neke dubrovačke tradicije, donosi gore spomenuti učeni talijanski dominikanac Serafino Razzi (1531. - 1611. ili 1613.) koji je u Dubrovniku boravio od 1587. do 1598. godine. Bio je to vrlo učen i plodan pisac, (napisao je 149 djela od kojih je znatan broj tiskan). ${ }^{19}$ Njegovo izvješće kao stranca (talijanskoga dominikanca) svakako je posebno zanimljivo, jer je podatke za svoje pisanje našao u Dubrovniku. U djelu La storia di Ragusa (koju on zove Raugia) također spominje prvoga po imenu poznatoga trebinjskog biskupa Ivana iz vremena vladara Bele Polimira (Pavlimira). I on počinje s Dukljaninovim opisom kako je Polimira, kada se iskrcao u Gružu, dočekao trebinjski biskup Ivan s barunima i odveo u Trebinje gdje su ga učinili kraljem. ${ }^{20}$

4. Dubrovački kroničar i povjesničar Džono Rastić (Junius Resti 1669. ili 1671. - 1735., treba ga razlikovati od istoimenoga dubrovačkog pjesnika koji je živio 1755. - 1814.) za razliku od Ranjine spominje trebinjskoga biskupa imenom Ivana (kao i Tuberon i Razzi) koji je dočekao Polimira Belu u Gružu. ${ }^{21}$

cura, et eleggendo in quella la sua habitazione, con autorità del Sommo Pontefice Benedetto V, transferì in essa la degnità et il titolo dell'Arcivescovado." S. Krasić - S. RazzI, nav. dj., str. 111.

18 D. Farlati - J. Coleti, Illyrici sacri, VI., Venetiis, 1800., str. 35-36; K. DraGanović, nav. dj., str. 241. Usp. i Serafino RazzI, Povijest Dubrovnika, na hrvatski preveli Iva Grgić i Stjepan Krasić, tekst margina prevela Anamarija Paljetak, Dubrovnik, 2011., str. 273-281.

19 S. Krasić - S. RazzI, nav. dj., str. 77-82. Vidi i popis djela: S. RazzI, nav. dj., str. 273-281.

20 "Quiui per tanto sbarcato Polimiro, fu da Giouanni Vescouo Tribuliense, e da i primi baroni del regno i quali per cagione d'honore, e di beniuolenza quivi erano venuti ad incontrarlo, condotto à Tribulio, in detta Città, secondo il costume di quel regno, vnto, e creato Re di Bossina, e di certa parte della Dalmazia." S. RAzzI, La storia di Raguza (Istoria di Raugia), Dubrovnik, 1903., str. 15. Autor grad zove "Raugia", a Trebinje "Tribulio", nav. dj., nenumerirana stranica iza str. LII, kao i na str. 15.

21 "Dopo qualche tempo Polimiro Belo, d'un' altra linea dei re de' Slavini, e per linea materna romano, nipote di Radoslavo, re parimente de' Slavini, il quale, scacciato a Roma, dove, dopo morta la prima, prese la seconda moglie di nazione romana, con la quale ebbe un figliuolo per nome Petrislavo, padre di Polimiro Belo: costui, ammazzato già Gotislavo, in una battaglia, senza discenden- 
Mavro Orbini (Marino Orbini, 1563. - 1614.), ne spominje biskupa Ivana, te za razliku od Dukljanina koji piše da je kralj Pavlimir "dok je ulazio u jedan grad Tribunjski" umro naprasnom smrću te ga pokopaše "u crkvi sv. Mihaela u istom gradu", on kaže "kad se zateknu u Trebinju pokosi ga iznenadna smrt te ga sahraniše tamo u crkvi sv. Mihaela".22

Povijesna znanost u svim vrstama izvora traži zrnce istine pa i u konfuznim kronikama u kojima su najčešće ipak istinita imena vladara, geografski nazivi i sl., ali je vrlo teško razlučiti istinu od legende i vlastitih domišljanja njihovih pisaca. Traži se doista studiozna i vrlo zahtjevna provjera na temelju autentične izvorne građe.

Prvo poznato ime trebinjskoga biskupa, Ivana, susrećemo dakle u trojice, a njegov spomen, ali bez imena, $u$ istim okolnostima i u četvrtoga dubrovačkog pisca-kroničara. To samo po sebi govori da ne bi trebalo olako prelaziti preko njegova imena u popisima trebinjskih biskupa. ${ }^{23}$

za, per ricuperar l'avito regno, chiamatovi anche da'Slavini, per le dissensioni tra loro nate, si pose in cammino, conducendo seco tutti li Slavini, discendenti di quelli che col suo avo Radoslavo s'eran ritirati a Roma. Pervenne in Puglia, dove imbarcatosi, con prospera navigazione arrivò nel porto di Gravosa, ora comunemente detto di Santa Croce, lontano da Ragusa un miglio in circa e capace di grossissima armata. Quivi fu incontrato, e ricevuto con ogni sommissione, da Giovanni vescovo di Tribunio, e da alcuni primati del suo regno, che vennero incontrar il propiro principe. I Ragusei gli fecero buona accoglienza, col che acquistarono e benevolenza e confidenza appresso la sua persona. Entrato Polimiro, colla comitiva condotta da Roma, e con quelli che vennero incontrarlo, nel proprio regno, fu ricevuto da tutti con applauso." NATKo NoDILO, "Chronica ragusina Junii Restii (ab origine urbis usque ad annum 1451) item Joannis Gundulae (1451 - 1484)", u: Monumenta spectantia Historiam Slavorum meridionalium, Scriptores, vol. II., Zagrabiae, 1893., str. 25.

22 "...trovandosi a Trebine, fu oppresso da subita morte et ivi sepelito nella chiesa di san Michele Arcangelo..." Ferdo Šišić, Letopis popa Dukljanina, Beograd, 1928., str. 322; Mavro Orbini, Kraljevstvo Slavena, Franjo Šanjek (prir.), prevela Snježana Husić, Zagreb, 1999., str. 281-282. Godine 1629. "stjepanski" biskup Dominik Andrijašević piše da se u crkvi sv. Petra u Zavali vide grobovi mnogih prvaka, a među njima i jednoga kralja Dalmacije zvanog Pavlimir. Krunoslav Draganović, "Tobožnja 'Stjepanska biskupija - Ecclesia Stephanensis' u Hercegovini", u: Croatia sacra, IV., 1934., str. 53. U novije je vrijeme Snježana Vasilj u Zavali otkrila i jedan veoma zanimljiv grob koji svakako predstavlja značajnu osobu, ali je nažalost opljačkan pa se može samo reći da je osoba bila od velike važnosti. SNJEžAna VASILJ, "A rheološki lokalitet Crkvina u Zavali, Općina Ravno. Revizija istraživanja iz 1957. godine", u: Hercegovina, Mostar - Zagreb, 4 - 2018., str. 49-86.

23 Biskupa Ivana ispušta npr. K. Draganović, nav. dj., str. 390, dok ga navodi D. Farlati - J. Coleti, nav. dj., VI., str. 288-290, te Bazilije Pandžić, "De dioecesi tribuniensi et mercanensi", u: Studia Antoniana, 12, Rome, 1959., str. 
Važno je napomenuti također da mu se ime veže i uz povijesne osobe. Trebinjskoga vladara imenom Belo nalazimo ne samo u Dukljanina i dubrovačkih kroničara nego i među vladarima koje navodi spis cara Konstantina Porfirogeneta ${ }^{24}$ kada piše o Trebinju (Travunji). Kroničar Ranjina u svome opisu spominje, samo malo prije ovoga vremena, i drugu povijesnu osobu, vladara Časlava čija je vladavina bila oko 933. - 950. godine. ${ }^{25}$ Osim Dukljanina, Ranjine i dr., što je osobito važno, o Časlavu piše i njegov suvremenik, pisac car Porfirogenet. ${ }^{26}$

Trebinjska je biskupija doista utemeljena nekada u drugoj polovici X. stoljeća, što je dokazano, ${ }^{27}$ pa ovdje o tomu nije potrebno pisati. Bilo je to u vrijeme kada je trebinjska oblast sa svojim vladarima igrala glavnu ulogu u Tribuniji i okolnim kneževinama, kako piše Tuberon i kako se zaključuje na temelju izgubljena "Trebinjskog rodoslova", ${ }^{28}$ ili kronike, sastavnice Dukljaninova ljetopisa. Zbog prekida odnosa s dalmatinskim gradovima i njihovim biskupijama tada je Trebinje, kao nekada Nin u Hrvatskoj i Ston u državi Mihaela Viševića, postalo biskupsko sjedište, vjerojatno opet, kako papa Lav VI. (928.) piše za Nin "probitate temporum". ${ }^{29}$ Trebinje je, naime, udaljeno samo dvadesetak km zračne linije od Dubrovnika. Barani su u sporu s Dubrovnikom za metropolitansko pravo tvrdili da se trebinjska oblast prostirala sve do dračke provincije, a da je jurisdikcija Dubrovačke biskupije bila samo do brda nad gradom. ${ }^{30}$

Dakako i u Dukljanina pa onda i u kroničara znanost otkriva mnoge netočne tvrdnje. Prije svega nisu nikada postojale metropolije u Epidaurumu niti u Diokleji. Epidaurum je, kao obična biskupija prema

83. O njemu usp. i Ivica Puljić, "Prva stoljeća trebinjske biskupije", u: IvicA Puljić (prir.), Tisuću godina trebinjske biskupije, (Studia vrhbosnensia, II.), Vrhbosanska visoka teološka škola, Sarajevo, 1988., str. 66.

24 Usp. K. Porfirogenet, nav. dj., poglavlje XXXIV., str. 89, 280.

25 O Časlavu usp. Konstantin JirečEK - Jovan Radonić, Istorija Srba, I., Beograd, 1981., str. 114-116; Vladimir Ćorović, Istorija Srba, I., Beograd, 1989. str. 98-101 i dr.

26 K. Porfirogenet, nav. dj., str. 86-88.

27 I. PuljIć, "Prva stoljeća trebinjske biskupije", str. 52-57.

28 V. MošIn, nav. dj., str. 33; E. PERIČIĆ, nav. dj., str. 37.

29 CD, I., str. 39.

30 "...ciuitas Ragusa nihil plus habet facere et non extenditur iurisdiccio, nisi vsque ad montem qui situs est ante ciuitatem Ragusinam". TADiJA SMIČIKLAS, Codex diplomaticus, IV., Zagreb, 1906., str. 482-483. 
papinskim pismima, dočekao seobu naroda. ${ }^{31} \mathrm{U}$ spisima sabora iz 925. i 928. godine Epidaurska se biskupija direktno ne spominje, ali je očito da biskupije Kotora i Dubrovnika nastoje spasiti legitimitet svoga postojanja oslanjajući se na njezino nasljedstvo. ${ }^{32}$ Biskupi Dubrovnika i Kotora trebaju sada pravedno podijeliti tu jedinstvenu biskupiju! ${ }^{33}$ Tvrdnja da je epidaurski ("nad")biskup izbjegao u Trebinje, kako piše Razzi, nije logična. Stječe se dojam da Razzi ovdje iznosi dubrovačku tvrdnju u borbi za metropolitansko pravo s Barom. (Ne može biti njegova osobna tvrdnja, jer on je stranac i piše, kako sam kaže, na temelju onoga što je čuo i pročitao u Dubrovniku!) Ta stvorena dubrovačka tradicija tvrdi da je Dubrovnik zapravo nasljednik ne samo epidaurske nego i dukljanske "metropolije". Epidaurski nadbiskup Ivan je, naime, ponio sa sobom naslov epidaurskoga nadbiskupa u izbjeglištvo $\mathrm{u}$ Trebinje. Odatle je taj epidaurski nadbiskupski naslov prenesen $\mathrm{u}$ Diokleju, odakle ga je, opet nadbiskup Ivan, ponio u novo izbjeglišstvo preko Mrkana u Dubrovnik. Tako je, prema toj tvrdnji, konačno taj stari naslov epidaurskoga "nadbiskupa" završio u Dubrovniku gdje se transformirao u naslov dubrovačkoga nadbiskupa pa Bar tu nema pravo ništa tražiti! Prvi biskup Mrkana spominje se tek 1322. godine. ${ }^{34}$ Domalo doznajemo da je riječ o trebinjskom biskupu Nikoli. ${ }^{35}$

Neodrživa su i pripovijedanja o vremenu uspostave nadbiskupija. Dubrovnik je 928. godine samo biskupija, a sjedište crkvene metropolije postao je tek u vrijeme pape Grgura V. (996. - 999.), kako se vidi iz bule pape Benedikta VIII. iz 1022. godine, iako je zove epidaurskom (Pitavritana). ${ }^{36}$ Vlastitu nadbiskupiju za svoju državu tražio

31 Ante Škegro, "The Dioecese of Epitaurum - Ecclesia Epitauritana", u: Histria Antiqua, 18/2, Pula, 2009., str. 203-216.

32 Usp. Ivica Puljıć, "Biskupije gornje Dalmacije na splitskim saborima 925. i 928. godine", u: Hercegovina, 4, Mostar, 2018., str. 31-47.

33 "VIII. De episcopis Ragusitano et Catharitano, quorum mani(fe)ste una sedis dignoscitur, ipsam diocesim equa lance inter se diuidant ita, ut si unus dicte ecclesie pastor obierit, donec ordinetur episcopus residens ipsius ecclesie ecclesiasticarum curam geret." CD, I., str. 24.

34 Monumenta ragusina, Libri reformationum, I., u: Monumenta spectantia historiam Slavorum meridionalium, X., Zagreb, 1879., str. 73, 102.

35 DADU, sig. 12, ser. I, No 2, f. 56; MARIJAn Sivrić, "Oporuke biskupa trebinjsko-mrkanske biskupije od 14. do 18. stoljeća", u: Hercegovina, 24, Mostar, 2010., str. 80; B. PAndžıć, nav. dj., str. 17, osobito bilj. 4. (Zabunom je godina 1326. zapisana kao 1236.).

36 Bula se čuva kao najstariji dokument u Dubrovačkom arhivu (bečka skupina, bez broja) i druga je (sačuvana) papinska bula pisana na pergameni. Više je puta objavljivana. Usp. CD, I., str. 61-62. 
je od pape Grgura VII. (1073. - 1085.) i dukljanski vladar Mihael, kako se vidi iz papina odgovora kojega je 1078. poslao Mihaelu: dobio je kraljevsku krunu ali ne i nadbiskupiju u svojoj zemlji sa sjedištem u Baru o čemu predlaže raspravu između Splita, Dubrovnika i Bara. Nadbiskupiju je za svoje kraljevstvo uspio dobiti tek njegov nasljednik kralj Bodin 1089., ali od protupape Klementa III. (Wiberta, 1080. - 1100.). ${ }^{37}$ Uspostava dviju metropolija za biskupije Gornje Dalmacije početak su višestoljetne borbe ova dva grada za metropolitansko pravo, ali i temelj pisanja svih kroničara o tobožnjim nadbiskupijama u Epidaurumu i Diokleji pa ih u tom svjetlu treba i razmatrati!

Ipak treba reći opet da su i kronike, ljetopisi i tradicije u nekoj mjeri, višoj ili manjoj, povijesni izvori druge ruke. Naime, kada npr. neki samostan svoje pravo na određeni posjed oslanja na falsificiranu ispravu, ipak u njoj ima prilično istine: oslanja se na sigurnu i tada svima poznatu povijesnu osobu kao donatora, u isto vrijeme siguran je dokaz da postoji i taj samostan kao i navedeni posjed o komu je riječ... Upitno je samo je li doista taj vladar darovatelj ili mu se to pripisuje... Tako je i u tvrdnjama kroničara zemljopisno nazivlje nedvojbeno, a i vladarska i biskupska imena su u velikoj mjeri povijesne osobe, dok sve drugo treba primiti s velikim oprezom.

\section{Zaključak}

Nekoliko dubrovačkih pisaca i kroničara spominje ime trebinjskoga biskupa Ivana koji je tako prvi imenom poznati trebinjski biskup. Međutim, kako ipak nije riječ o izvorima prve ruke, ne mogu se $s$ punom sigurnošću ove vijesti uzeti kao sigurne. Ipak, okolnosti u kojima biskupa toga imena, i to više kroničara spominje, svaki s nekim svojim vlastitostima pa u ponečemu i različitostima, govori da nije riječ o pukom prepisivanju. Osim toga, njihove se vijesti dobro uklapaju u vremenski okvir i okolnosti druge polovice X. stojeća, kada je Trebinjska biskupija sigurno utemeljena, pa bi se njihovo pisanje i ime biskupa Ivana moglo bez imalo ustručavanja navoditi u popisima trebinjskih biskupa.

37 Milan Šufflay, Acta et diplomata Albanae illustrantia, I., Vindobonae, 1913., str. 21; E. PERIČIĆ, nav. dj., u prilozima iza str. 273; I. Jovović, nav. dj., str. 237-240. 


\section{Chroniclers and historians about the first known Trebinje Bishop Ivan}

On the occasion of the $200^{\text {th }}$ anniversary of death of the last Trebinje-Mrkan Bishop Nikola Feric

\section{Summary}

It was determined for sure that Diocese of Trebinje was established in the second half of the $10^{\text {th }}$ century, and it is not strange that neither the documents related to its establishment nor the names of its first bishops were preserved, because even the names of rulers from that period are hardly known. Since in this year, 2019, is the $200^{\text {th }}$ anniversary of death of the last TrebinjeMrkan Bishop Nikola Feric (1792-1819), it seems convenient to reveal what is a legend and what is historical truth in different lists about its first Bishop mentioned by name. Namely, few writers and chroniclers from Dubrovnik mentioned the name of Trebinje Bishop Ivan, who is therefore the first Bishop of Trebinje known by the name. However, since those are not firsthand sources, these news cannot be taken as true for sure. Nevertheless, circumstances in which the bishop of that name is mentioned by many chroniclers, say that this is not mere rewriting. Moreover, their news fit well in the time framework and circumstances of the second half of the $10^{\text {th }}$ century when Trebinje Diocese was established for sure. Therefore, their writing and the name of Bishop Ivan could be mentioned in the lists of Trebinje bishops without any reservation.

Keywords: Trebinje Diocese; Trebinje Bishop Ivan; Trebinje; Tribunija-Trebinje; Diokleja; Epidaurum; Dubrovnik; Bar. 